\title{
Computational investigation of flame characteristics of a non-propagating shrub fire
}

\author{
Satyajeet Padhi ${ }^{\mathrm{a}}$, Babak Shotorban ${ }^{\mathrm{a}, *}$, Shankar Mahalingam ${ }^{\mathrm{a}}$ \\ ${ }^{a}$ The University of Alabama in Huntsville, Huntsville, AL 35899 USA
}

\begin{abstract}
A three-dimensional multiphase, physics-based model based on large eddy simulation methodology was used to investigate a model shrub fire at a statistically stationary state. Governing equations of the solid phase were modified to achieve this state at which a detailed analysis of the flame and plume is possible through time averaging. The computations were performed for shrub bulk densities ranging from 1 to $6 \mathrm{~kg} / \mathrm{m}^{3}$ and corresponding time-averaged flame heights were recorded. The continuous flame zone, intermittent flame zone and thermal plume region were identified. It was found that flame height scales as the two-fifth power of heat release rate for a mean flame tip temperature of $800 \mathrm{~K}$. The slopes of temperature and velocity profiles along the centerline in the continuous and thermal plume region were consistent with the corresponding slopes for buoyant diffusion flames over porous burners. First-order and second-order statistics were investigated and it was found that there is a strong correlation between velocity and temperature in the continuous flame region. This was attributed to the strong buoyancy accelerations due to combustion of pyrolysis gases from the shrub. Investigation of vortical structures formed in the fire plume showed that strain dominates the flow in the continuous flame region with large scale vortices forming downstream in the plume region.
\end{abstract}

Keywords: Wildland fires; Wildland fire modeling; Large eddy simulation

${ }^{*}$ To whom correspondence should be addressed

Email address: babak.shotorban@uah.edu (Babak Shotorban ) 


\section{Introduction}

3

4

5

The purely buoyant turbulent fire plume has been an important topic of study in fire science. These type of flows are of interest due to their practical applications in wildland fires, building fires, and the design of fire-prediction tools and fire-protection systems. Many theories, experiments, and simulations have been performed to understand purely buoyant turbulent fire plumes from different types of fire sources, and various correlations have been proposed for flame height, temperature and velocity profiles, air entrainment, etc.

Some of the earliest analytical works on fire plumes were carried out by Morton [1] and Nielsen [2] by accounting for temperature and density changes within the plume, energy released by combustion, air entrainment and heat lost due to radiation. The simplified conservation equations were numerically integrated to predict variations in temperature, velocity and plume width along the plume axis.

Extensive research has been carried out to study fire plumes from pool fires [3-12], where correlation have been proposed for flame height and heat release rate. The entrainment rate into the fire plume is characterized, and the different regions in a fire plume, i.e., continuous, intermittent and plume region have been identified. Various fluid mechanical characteristics such as puffing phenomena were studied as well.

While fire plume in the context of experimental pool fires has a steady rate of fuel supply, fire plumes in the context of vegetative fuels are unsteady. Several attempts have been made to characterize the properties of flames from wildland fuels. Albini [13] proposed a onedimensional model for the structure of the wind-blown turbulent flame from a line fire over a vegetative fuel bed in which buoyancy was the principal source of vertical momentum. The volume of air entering the flame zone was assumed to be proportional to the ambient wind speed. Also, chemical reactions representing flaming combustion were included. Approximate expressions were obtained for flame height, length and tilt angles with a satisfactory agreement with experimental data.

Nelson and Adkins $[14,15]$ using the data from a series of wind-driven experimental and field fires determined correlations among variables affecting the rate of spread of wild- 
fire. Dimensional analysis was used to derive correlations between fuel consumption, flame residence time, and wind speed and their effect on the rate of spread of fires in a forest. Mendes-Lopes et al. [16] performed an extensive set of experiments on fire spread in fuel beds. They reported that the rate of spread of fire increased with wind and with slope for up-hill propagation. Flame angle and flame heights were also found to be dependent on wind velocity, slope, and fuel moisture content.

Sun et al. [17] investigated fire behavior for three common chaparral fuels, chamise, manzanita, and ceanothus, by burning them in a cylindrical container. The observed fire behavior included mass loss rate, flame height, and temperature structure above the burning fuel bed. The flow velocities in the fire plume were studied using thermal particle image velocimetry (TPIV). Power laws were extracted for flame heights of live and dead fuels with respect to the heat release rate.

Along with the experimental works performed to study wildland fire behavior, numerical simulations have been used extensively to further the understanding of wildland fires. One of the most sophisticated tools used for numerical analysis of wildland fires is physics-based fire behavior models. These models solve a complete set of governing conservation equations (mass, momentum, energy and species) and include the three modes of heat transfer and combustion. Physics-based wildland fire models have been developed over the last twentyfive years for studying wildfire behavior at various length scales [18-23]. While most of the studies focus on fire behavior in surface fuel beds [19, 22, 24-27], very few studies have been performed to study fire behavior in shrubs [28]. These numerical studies focus on extracting fire spread rates through the fuel matrix, mass loss rates, heat release rates and identify the dominant modes of heat transfer which govern the fire behavior.

The objective of this paper is to obtain statistical correlations between flame and plume dynamic variables in a non-propagating shrub fire. These correlations are developed for the mean flame heights versus the mean heat release rate, and the spatial variations of means and variances of velocity and temperature fields through physics-based modeling. Hence, the properties of flames from a statistically stationary shrub fire were studied using a modified version of a previously developed physics-based model [21, 22, 28]. Various bulk densities of 
chamise shrub were considered to obtain flame heights, and first- and second-order statistics of temperature and velocity fields. A detailed description of the problem statement is given in Section 2, with the approach adopted to achieve a statistically stationary state for a shrub fire explained in Section 2.1. In Section 3, the results describing the key characteristics of stationary shrub fires are presented, followed by the conclusions in Section 4 .

\section{Problem description}

\subsection{Stationary shrub fire model}

The burning of an isolated chamise shrub in still, open environment is considered here. As time evolves, the shrub mass is consumed until burning terminates. Since the variables of interest fluctuate randomly over time and space, a more detailed description of the fire dynamics can be achieved by expressing them in statistical terms, e.g., averages, variances, and covariances of temperature and velocities. Since burning is an inherently transient process, the statistics of properties such as temperature and velocity are not independent of the time origin. Also, a lack of statistical homogeneity in any spatial direction precludes any statistical analysis. Although, it is possible to conduct an ensemble averaging, the computational cost of a single simulation using large-eddy simulation (LES) is too high to allow the modeling of a large number of sample problems and calculate statistics based on ensemble averaging. In order to circumvent this problem, an idealized shrub fire which is statistically stationary is developed here. A process is statistically stationary if all multitime statistics are invariant under a shift in time [29]. Such an approach facilitates a detailed statistical analysis of the fire plume through time averaging.

In order to achieve a statistically stationary state for shrub fires, the following assumptions were made: (i) the mass and temperature of the shrub remain constant during the burning process, (ii) moisture content of the shrub is negligible, (iii) contribution of char oxidation is negligible, (iv) the flame is generated from the combustion of pyrolysis gases released at a constant rate from a fixed amount of vegetation.

The amount of pyrolysis gases released is governed by an Arrhenius-type law and is given 
by,

$$
\dot{\rho}_{\mathrm{pyr}}=A \rho_{\mathrm{s}} \exp \left(-T_{\mathrm{a}} / T_{\mathrm{s}}\right),
$$

where $\dot{\rho}_{\text {pyr }}$ is the constant rate of production of pyrolysis gases from a fixed shrub bulk density $\rho_{\mathrm{s}}$ and a fixed solid phase temperature $T_{\mathrm{s}}$. The pre-exponential factor $A$ is $3.63 \times 10^{4} \mathrm{~s}^{-1}$ and the activation temperature, $T_{\mathrm{a}}=7250 \mathrm{~K}[19]$. The amount of dead material in a vegetation canopy which can undergo combustion is characterized by its bulk density. Bulk density of a shrub is defined as the oven dry mass of foliage and small twig (less than 3 $\mathrm{mm}$ in diameter) per unit volume of shrub [30]. Typical bulk densities reported for chamise in southern California chaparral range from 1.5 to $9 \mathrm{~kg} / \mathrm{m}^{3}$ [31]. Thus, six different bulk densities ranging from 1 to $6 \mathrm{~kg} / \mathrm{m}^{3}$ are considered in this work. Thermal decomposition of pine needles studied by Thermogravimetric Analysis (TGA) showed that the wood sample is completely dehydrated starting at $400 \mathrm{~K}$, and degradation intensifies by pyrolysis at a solid phase temperature of $460 \mathrm{~K}$ [20]. Hence, the shrub temperature is fixed at $T_{\mathrm{s}}=500 \mathrm{~K}$.

The model developed for this work closely resembles the approach by Nmira et al. [32]. They used a three-dimensional physics-based model to study flame characteristics for steady fires from porous vegetative fuel beds. Nmira et al. [32] solve the mean gas flow field by the Reynolds-averaged Navier-Stokes (RANS) equation set closed by Renormalization Group (RNG) $k-\epsilon$ turbulence model. Whereas, this work solves the gas phase conservation equations using large eddy simulation. Also, they used a desired heat release rate to obtain a constant rate of production of pyrolysis gas, while this work uses a constant rate of production of pyrolysis gases produced from a fixed bulk density of the shrub (See Eq.1). While Nmira et al. [32] study the effect of wind on flame characteristics from isolated and line fire sources with different height to depth ratios for the fuel bed, this work focuses on flame characteristics from isolated chamise shrub fires with various bulk densities in the absence of a crosswind.

\subsection{Computational methodology}

A detailed description of the three-dimensional physics-based multiphase model utilized in this work can be found in Dahale et al. [28] and references therein. Only a brief description 
is provided here. A set of three-dimensional transport equations is solved for the conservation of mass, momentum, energy, chemical species and soot evolution in the gas phase. The solid phase is assumed to be a porous medium with thermally thin elements. Combustion is initiated by an auto-ignition process facilitated by the hot solid shrub fuel. The solid phase influences the gas phase via the drag force arising from resistance to fluid flow through the porous shrub. Since the mass and temperature of the solid phase is kept constant to achieve a statistically stationary state, equations governing the evolution of mass and temperature of solid phase are not solved. Energy transfer from the solid phase to the gas phase also includes convection and radiation heat transfer. Various source terms appearing in the conservation equations can be summarized as: mass exchange between solid and gas phase in the continuity equation, drag forces arising due to the presence of solid fuel particles in the flow field in the momentum equation, convective and radiative heat exchange between the solid and gas phases in the energy equation, mass exchange due to combustion and the chemical source term in the species transport equation, and soot formation due to pyrolysis in the soot transport equation. The gas phase species considered in this work are $\mathrm{CO}, \mathrm{CH}_{4}, \mathrm{H}_{2}, \mathrm{CO}_{2}$ [33]. The turbulent flow field generated due to the combustion process is modeled using large eddy simulation (LES). The subgrid scale (SGS) stress in the momentum equation is modeled by a dynamic Smagorinsky model, and the SGS energy and species fluxes are modeled by a gradient diffusion model. The turbulent combustion model using a single step global reaction mechanism is based on a flame surface density concept [34]. A radiation transport equation is solved to account for the radiative heat exchange within the gas phase, and between the solid and gas phases. The thermal radiation solver is based on a finite volume implementation of the discrete ordinate method. The major contributors to flame radiation in fires are incandescent soot particles. Hence, to obtain a more accurate description of thermal radiation a soot transport equation is solved.

The governing equations are discretized in a three-dimensional Cartesian coordinate system on a uniform rectangular mesh, using a finite volume formulation and a staggered grid arrangement. For the gas phase equations, the Quadratic Upwind Interpolation for Convective Kinematics with Estimated Streaming Terms (QUICKEST) finite volume scheme 
is used for spatial discretization of convective and diffusive terms while an explicit Leith-type temporal discretization is used for the time derivative terms [35, 36]. This scheme is thirdorder accurate in space and time. The pressure-velocity coupling is solved using a projection method. Open boundary conditions are used on all lateral boundaries, wherein gradients of flow variables normal to the boundary are set to zero allowing for inflow and outflow such that fluid can be entrained into the domain through the surface normal direction. A convective boundary condition is employed at the top boundary, where the convection velocity is set equal to local normal velocity calculated at the cell adjacent to the boundary. The bottom boundary is modeled with a free slip wall boundary condition so that no mass enters or exits across this boundary.

The computational model has been tested and validated by Dahale et al. [28] for a nonstationary shrub fire. The validation was conducted for laboratory-scale shrub fire under no-wind conditions. The modeling results were validated against the experimental results of Li [31]. Parameters such as burning time, total mass consumed, spread rates and the time required to reach maximum mass loss rate were in good agreement. A detailed description of the validation study can be found in Dahale et al. [28] and is hence not repeated here.

The schematic of the computational setup is shown in Fig. 1 along with the typical dimensions of a chamise shrub. The solid phase in this study represents a chamise shrub, which is assumed to be a porous medium with only foliage. The height of the shrub is 70 $\mathrm{cm}$ with a maximum diameter of $60 \mathrm{~cm}$ and is located along the axis of symmetry of the domain. Its shape and size were chosen based on the experimental [31] and modeling studies [28]. The thermophysical properties of the solid phase are assumed to be constant within the shrub. The dimensions for the computational domain are chosen to be $2.4 \times 9.6 \times 2.4 \mathrm{~m}$. A uniform mesh with a resolution of $120 \times 480 \times 120$ is used. This choice of domain size is dictated by the need to capture the plume inside the computational domain and avoid the potential impact of the treatment of boundary conditions on the region of interest. Our choice of grid resolution is guided by experimentally validated numerical studies of shrub fires by Zhou et al. [22] and Dahale et al. [28]. 


\section{Results and discussion}

Flame heights depend strongly on the heat release rate of fire $[37,38]$. The heat release rate in this study is computed from the source term for chemical reactions in the gas phase energy conservation equation, i.e. $\int_{V}\left(\sum_{K=1}^{N_{K}} \dot{\omega}_{K} \Delta h_{f, K}^{0}\right) d V$, where $\dot{\omega}_{K}$ is the production rate for the $K^{\text {th }}$ gas phase species, $\Delta h_{f, K}^{0}$ is the enthalpy of formation for the $K^{\text {th }}$ gas phase species, $N_{K}$ is the total number of gas phase species and is integrated over the entire computational domain $V$. The resulting time-averaged heat release rates for the six bulk densities considered in this study ranges between 30 and $400 \mathrm{~kW}$. Flame length data discussed in experimental works on purely buoyant diffusion flames over porous burners[3, 4, 39-41], pool fires $[11,42,43]$ and vegetation fuels $[17,38]$ have provided scaling laws for flame height and showed that flame height $(H)$ scales as the two-fifth power of heat release rate $(\dot{Q})$, i.e., $H=0.2 \dot{Q}^{2 / 5}$. Several authors have used flame temperature to identify flame tip heights. Albini [13] reported the flame tip to occur at a height at which the mean temperature falls to $500 \mathrm{~K}$. Sullivan et al. [44] reported flame tip temperature to be $573 \mathrm{~K}$ in their study on Australian bush fires. Nmira et al. [32] in their work on steady vegetation fires using RANS models used a temperature of $500 \mathrm{~K}$ to identify the flame tip height. Whereas, Heskestad [43, 45] and Tang et al. [46] adopt the criterion of a temperature rise of $500 \mathrm{~K}$ above ambient, i.e., $800 \mathrm{~K}$, to define the flame tip height. In this work, a flame tip temperature of $800 \mathrm{~K}$ is used to identify the flame height. Flame heights were measured from the top surface of the shrub $(y=1.0 \mathrm{~m})$. The correlation of $H=0.2 \dot{Q}^{0.45}$ between flame height and heat release rate was obtained which is in good agreement with the correlation obtained for previous studies on fire plumes from pool fires [43], flames over porous burners [4] and vegetative fuels [38].

A dimensionless heat release rate $Q^{*}$ is often used to classify fire types and classify flame behavior, such as flame height [8]. The dimensionless heat release rate is defined as $Q^{*}=\dot{Q} /\left(\rho_{\infty} C_{p \infty} T_{\infty} D^{2} \sqrt{g D}\right)$, where $\dot{Q}$ is the heat release rate, $D$ is the diameter of the fire source, $\rho_{\infty}, C_{p \infty}, T_{\infty}$ are density, specific heat capacity and temperature of ambient air, and $g$ is the acceleration due to gravity. The dimensionless flame heights, defined as $H / D$, 
are shown in Fig. 2 in the form of a scatter plot of $H / D$ versus $Q^{*}$. For comparison, the dimensionless results of Cetegen [4] obtained for natural gas flames over porous refractory burners over two regimes of $Q^{*}$ and pool fires [43] are also shown in the figure. The correlation by Heskestad covers the entire range of $Q^{*}$ except for the momentum regime and follows a two-fifth power law. The dimensionless flame height correlation obtained for stationary shrub fire was $H / D=4.5 Q^{* 0.45}$. The difference in the constant for the scaling law can be due to various reasons. The correlations obtained for pool fires and buoyant diffusion flames over porous burners do not account for in-depth combustion, such as combustion in wood cribs or shrubs where air can entrain into the burning fuel matrix. The effects of density of the fuel gas on the ambient density also play a role in determining the flame heights [47].

It was observed that for the resolution reported in this study (2 $\mathrm{cm}$ grid spacing), the flame height scales with heat release rate with an exponent of 0.45 , consistent with the works of Dupuy et al. [38] and Sun et al. [17]. On the other hand, for a coarser resolution $(4 \mathrm{~cm}$ grid spacing) we found that the flame height scales with heat release rate with an exponent of 0.97 . The change in the value of exponent of heat release rate with grid resolution can be attributed to the change of the contribution of the subgrid scale (SGS) terms in the LES model. These terms are dependent on the filter size, which is equal to the grid size and changes with the change of grid resolution. As the grid is refined, more turbulent small scales are resolved, and the influence of the SGS terms is reduced. Thus, the LES results regardless of the truncation errors are grid dependent unless the grid size is very small, comparable to Kolmogorov length scale, in which case LES practically becomes DNS (Direct Numerical Simulation). Conducting a DNS for the problem in hand requires a very large grid points, which is not practical due to computational constraints.

McCaffrey [3] in his extensive work on measurement of temperatures in turbulent diffusion flames, identified three different regimes in a fire plume - continuous flame region, intermittent flame region and the thermal plume region. The temperatures observed in the continuous flame region were about $1200 \mathrm{~K}$, whereas in the intermittent flame region the temperatures reported were about 573 K. Fig. 3 shows the contours of instantaneous gas phase temperature for three bulk densities $\left(1,3,5 \mathrm{~kg} / \mathrm{m}^{3}\right)$. The temperatures observed in 
the continuous flame region were of the order of $1200 \mathrm{~K}$. The time-averaged gas phase temperature of $573 \mathrm{~K}$ is superimposed on the instantaneous temperature contours to indicate the location of intermittent flame. Beyond the intermittent flame region, significant fluctuations in temperature were observed in the thermal plume region. For a bulk density of 1 $\mathrm{kg} / \mathrm{m}^{3}$, continuous flame region is till $\mathrm{y} \approx 2.2 \mathrm{~m}$, intermittent flame region is between $2.2 \lesssim$ $\mathrm{y} \lesssim 3.5 \mathrm{~m}$, and plume region is from $\mathrm{y} \gtrsim 3.5 \mathrm{~m}$. Similarly, for a bulk density of $3 \mathrm{~kg} / \mathrm{m}^{3}$, continuous flame region is till $\mathrm{y} \approx 3.2 \mathrm{~m}$, intermittent flame region is between $3.2 \lesssim \mathrm{y} \lesssim 4.5$ $\mathrm{m}$, and plume region is from $\mathrm{y} \gtrsim 4.5 \mathrm{~m}$ and for a bulk density of $5 \mathrm{~kg} / \mathrm{m}^{3}$, continuous flame region is till $\mathrm{y} \approx 4.2 \mathrm{~m}$, intermittent flame region is between $4.2 \lesssim \mathrm{y} \lesssim 5.0 \mathrm{~m}$, and plume region is from $\mathrm{y} \gtrsim 5.0 \mathrm{~m}$ as seen in Fig. 3 .

Centerline profiles for time-averaged resolved axial velocity as a function of plume axial location for various bulk densities are shown in Fig. 4a. The profiles shown are obtained from the top of the shrub. The continuous flame region is dominated by buoyancy accelerations due to combustion of pyrolysis gases. The initial increase in axial velocity is a result of buoyancy-induced acceleration, which is due to the combustion in continuous flame zone. As one moves along the plume axis, the velocity reaches a maximum and then begins to decrease. This decrease can be attributed to the turbulent mixing caused by the surrounding air. Centerline profiles for the time-averaged resolved gas-phase temperature as a function of plume axial location for various bulk densities are shown in Fig. 4b. The temperatures are highest close to the top of the shrub, in the region of continuous flame, and decrease thereafter because of enhanced turbulent mixing with the surrounding air. In the continuous flame region, the time-averaged axial velocity profile along the centerline exhibits a slope of $y^{1 / 2}$, and the time-averaged temperature profile along the centerline exhibits a zero slope. In the plume region, the time-averaged axial velocity profile along the centerline follows a decay rate proportional to $y^{-1 / 3}$ and the time-averaged temperature profile along the centerline follows a decay rate proportional to $y^{-5 / 3}$, where $y$ is the vertical height. The nature of the temperature and velocity profiles is consistent with that obtained in experiments on buoyant turbulent plumes over porous burners by McCaffrey [3].

The centerline root mean square (r.m.s.) of velocity normalized by time-averaged cen- 
terline velocity and centerline r.m.s. of temperature normalized by temperature difference between the local and ambient values $\left(\Delta T=T-T_{a}\right)$ are shown in Fig. 5. The fluctuations of velocity and temperature at the centerline increase very rapidly to maximum values but subsequently decrease to reach nearly constant levels downstream. It can be seen from Fig. 4 and Fig. 5, that the peak values of velocity and temperature fluctuations are achieved at locations further down the fire plume compared to mean velocity and temperature peaks. The peaks of velocity and temperature are achieved in the continuous flame region whereas the peaks of corresponding fluctuations are achieved near the intermittent flame region.

The velocity-temperature correlation defined as $\left\langle v^{\prime} T^{\prime}\right\rangle /\left\langle v^{\prime 2}\right\rangle^{1 / 2}\left\langle T^{\prime 2}\right\rangle^{1 / 2}$, where angle brackets indicate time-averaging, along the centerline is shown in Fig. 6. It is clear that the temperature and velocity fields are strongly coupled in a buoyancy dominated flow. The magnitude and extent of correlation in the vertical direction depends on the heat released by the combustion of shrub fuel. It can be seen that the velocity-temperature correlations reach near constant values in the plume region and are very close to the experimental observations of George et al. [48] who reported values in the range of 0.7 in the plume region for $\left\langle v^{\prime} T^{\prime}\right\rangle /\left\langle v^{\prime 2}\right\rangle^{1 / 2}\left\langle T^{\prime 2}\right\rangle^{1 / 2}$.

The contribution to heat flux by turbulence along the plume can be examined by the ratio of turbulent to mean convective heat flux. The turbulent convective heat flux per unit area is given by $\left\langle v^{\prime} T^{\prime}\right\rangle$ and the mean convective heat flux per unit area is given by $\langle v\rangle\langle T\rangle$. The axial distribution of the ratio of the turbulent convective heat flux to mean convective heat flux is shown in Fig. 7. It can be seen that the percentage of mean convective heat flux carried by turbulence varies between 10 to $20 \%$. The peaks of the convective heat flux were observed in the intermittent flame region where temperature fluctuations are maximum due to the fluctuations of flame tip. As the plume develops, air is drawn into it from the lateral boundaries. This is called air entrainment and is a direct consequence of the engulfment of fluid by the coherent, vortical structures. Fig. 8 shows the mass flux at various heights of the domain. As we move upwards along the fire plume, more air is drawn into the plume due to enhanced mixing resulting from the turbulent plume. The higher the bulk density, the higher is the heat released and more air is entrained in order to mix with the combustible 
pyrolysis gases to carry out the combustion reaction. The resulting combustion reaction results in buoyancy accelerations which results in increased lateral air entrainment in the thermal plume region.

The time-averaged transverse profiles for resolved velocity and temperature rise are shown in Fig. 9. The profiles are obtained in the continuous, intermittent and thermal plume region. In the continuous flame region, the profiles are obtained at a height where the gas phase temperature is $873 \mathrm{~K}$. In the intermittent flame region, the profiles recorded at a height where the gas phase temperature is $573 \mathrm{~K}$, and in the plume region a temperature of $373 \mathrm{~K}$ is chosen to determine the height at which the profiles are to be determined. The vertical velocity is normalized by the centerline vertical velocity and temperature rise is normalized by the temperature rise along the centerline. The figures show the extent of plume spread in the lateral directions. The faster the velocity decays, the faster the plume spreads in the lateral directions. It can be seen that the plume spreads rapidly as one moves upwards along the plume axis. In regions closer to the fire source, Fig. 9a and Fig. 9b, the temperatures and velocities are higher due to buoyancy acceleration of the combustion gases released from the burning shrub. In the thermal plume region however, Fig. 9e and Fig. 9f, the velocity and temperature profiles spread rapidly by the increase of air entrainment from the lateral directions. The transverse profiles for r.m.s. of axial velocity and r.m.s. of temperature for various bulk densities at the corresponding locations are shown in Fig. 10. It can be seen that the fluctuations of velocity and temperature along the lateral directions are maximum at the plume boundaries due to shearing between the plume and the ambient air. The velocity and temperature fluctuations have approximately similar peak values for various heights along the plume axis.

The flames generated from a free-standing fire fall in the category of buoyancy-driven turbulent diffusion flames. The heat release due to combustion reduces the density in the flame resulting in an increase in the local buoyancy along the flame height. The buoyancy acceleration leads to the formation of vortical structures which grow into instabilities along the flame height. Fig. 11a shows an instantaneous snapshot of three-dimensional isosurfaces of vorticity magnitude at $30 \mathrm{~s}^{-1}$ (yellow) and $60 \mathrm{~s}^{-1}$ (red) for a bulk density of $3 \mathrm{~kg} / \mathrm{m}^{3}$. The 
second invariant of velocity gradient tensor can be used to locate the coherent structures formed due to the turbulent flow. The second invariant of velocity gradient tensor is defined as $\Pi=\left(|\tilde{\Omega}|^{2}-|\tilde{S}|^{2}\right) / 2$, where $\Omega$ is the rate-of-rotation tensor and $S$ is the strain-rate tensor. It identifies vortices as flow regions where $\Pi>0$ [49]. The isosurfaces of instantaneous second invariant of the velocity gradient tensor for a bulk density of $3 \mathrm{~kg} / \mathrm{m}^{3}$ are shown in Fig. 11b. It was observed that the strain rate is greater than vorticity in the continuous flame region, i.e. $\mathrm{y} \approx 3.2 \mathrm{~m}$. This can be attributed to the high buoyancy accelerations near the source of the fire due to the combustion of pyrolysis gases. As we transition into the intermittent region of the plume, i.e. $3.2 \lesssim \mathrm{y} \lesssim 4.5 \mathrm{~m}$, the flow breaks down into small scale vortices as seen in the intermittent region in Fig. 11. And in the plume region, i.e. $\mathrm{y} \gtrsim 4.5$ $\mathrm{m}$, these small eddies grow into large scale vortices with large values of rate of rotation. The flow field looks rather random and is mainly composed of small eddies which could be due to entrainment of the surrounding air into the plume. It can be seen that gaps exist within the plume which is probably an important mechanism for entrainment of ambient air by the plume. An analysis of the instantaneous snapshots of temperature does not show any puffing behavior that is observed in pool fires. The puff cycle in pool fires is formed by the formation of a base instability near the edge of the plume which grows due to misalignment of pressure and radial density gradients generating a localized torque. The toroidal vortex thus formed is destroyed which is due to the formation of secondary instabilities leading to the puffing behavior [50]. However, in the current study, the instabilities fail to form near the top surface of the shrub, which could be due to the porous nature of the shrub. Subsequently, the instabilities are not formed which could lead to a noticeable puffing behavior. However, as seen in the Fig. 11, the vorticity is significant in the intermittent and plume regions due to the formation of coherent structures resulting from the enhanced mixing due to entrainment of air into the thermal plume.

\section{Conclusions}

A qualitative and quantitative description of the flow field generated due to the steady burning of a shrub was described using a physics-based model. The steady burning was 
achieved by introducing a model shrub in which the rate of pyrolysis, the solid phase temperature and mass of the solid phase were kept constant. It was concluded that buoyancy acceleration plays an important role in the development of the plume in a statisticallystationary fire. The decay rates of velocity and temperature profiles in the continuous flame region and thermal plume region were consistent with those found in literature. First- and second-order statistics were calculated, which showed a strong correlation between velocity and temperature fields in the continuous flame region. A mean flame tip temperature of $800 \mathrm{~K}$ was used to obtain a scaling relationship between flame height and heat release rate which is in good agreement with the two-fifths power law. The differences observed in the correlation, such as the proportionality constant and the exponent for heat release rate could be attributed to the porous nature of the fuel source and in-depth combustion. The porous nature of the shrub affects air entrainment into the shrub, thus affecting the nature of the fire plume. The instantaneous vorticity magnitude and second invariant of velocity-gradient tensor fields were used to study the flow field generated from the shrub fire and locate the various coherent flow structures formed in the fire plume. It was found that strain dominates the flow in the continuous flame region with large scale vortices forming in the plume region.

\section{Acknowledgements}

This work was supported in part by the National Science Foundation (grant number CBET-1049560) and the 2013 Individual Investigator Distinguished Research (IIDR) program at The University of Alabama in Huntsville (UAH). Computational resources were provided by the Alabama Supercomputer Center (ASC), and the High Performance Technical Computing (HPTC) facilities at UAH.

[1] B. R. Morton, Modeling fire plumes, 10th Symposium (International) on Combustion, The Combustion Institute, Pittsburgh 10 (1965) 973-982.

[2] H. J. Nielsen, L. N. Tao, The fire plume above a large free-burning fire, 10th Symposium (International) on Combustion, The Combustion Institute, Pittsburgh 10 (1965) 965-972.

[3] B. McCaffrey, Purely buoyant diffusion flames - some experimental results, NBSIR 79-1910, National Bureau of Standards, Washington (1979). 
[4] B. M. Cetegen, Entrainment and flame geometry of fire plumes, Ph.D. thesis, California Institute of Technology (1982).

[5] M. A. Delichatsios, Air entrainment into buoyant jet flames and pool fires, Combustion and Flame 70 (1987) 33-46.

[6] G. Heskestad, Fire plume air entrainment according to two competing assumptions, Twenty-first Symposium (International) on Combustion 21 (1986) 111-120.

[7] J. G. Quintiere, B. S. Grove, A unified analysis for fire plumes, Twenty-Seventh Symposium (International) on Combustion 27 (1998) 2757-2766.

[8] E. E. Zukoski, T. Kubota, B. Cetegen, Entrainment in fire plumes, Fire Safety Journal 3 (1981) 107-121.

[9] Y. Xin, J. Gore, K. B. McGrattan, R. G. Rehm, H. R. Baum, Large eddy simulation of buoyant turbulent pool fires, Proceedings of the Combustion Institute 29 (2002) 259-266.

[10] T. G. Ma, J. G. Quintiere, Numerical simulation of asxi-symmetric fire plumes: accuracy and limitations, Fire Safety Journal 38 (2003) 467-492.

[11] Y. Wang, P. Chatterjee, J. L. de Ris, Large eddy simulation of fire plumes, Proceedings of the Combustion Institute 33 (2011) 2473-2480.

[12] S. C. P. Cheung, G. H. Yeoh, A. L. K. Cheung, R. K. K. Yeun, S. M. Lo, Flickering behavior of turbulent buoyant fires using large-eddy simulation, Numerical Heat Transfer, Part A 52 (2007) 679-712.

[13] F. Albini, A model for the wind-blown flame from a line fire, Combustion and Flame 43 (1981) 155-174.

[14] R. M. Nelson Jr., C. W. Adkins, Flame characteristics of wind-driven surface fires, Canadian Journal of Forest Research 16 (1986) 1293-1300.

[15] R. M. Nelson Jr., C. W. Adkins, A dimensionless correlation for the spread of wind-driven fires, Canadian Journal of Forest Research 18 (1988) 391-397.

[16] J. M. C. Mendes-Lopes, J. M. P. Ventura, J. M. P. Amaral, Flame characteristics, temperature-time curves, and rate of spread in fires propagating in a bed of pinus pinaster needles, International Journal of Wildland Fire 12 (2003) 67-84.

[17] L. Sun, X. Zhou, S. Mahalingam, D. R. Weise, Comparison of burning characteristics of live and dead chaparral fuels, Combustion and Flame 144 (2006) 349-359.

[18] A. M. Grishin, Mathematical modeling of forest fires and new methods of fighting them, Tech. rep., Publishing House of Tomsk State University, Tomsk, Russia (1997).

[19] B. Porterie, D. Morvan, J. C. Loraud, M. Larini, Firespread through fuel beds: modelling of wind aided fires and induced hydrodynamics, Physics of Fluids 12 (2000) 1762-1782.

[20] D. Morvan, J. L. Dupuy, Modeling of fire spread through a forest fuel bed using a multiphase formulation, Combustion and Flame 127 (2001) 1981-1994.

[21] X. Zhou, S. Mahalingam, D. R. Weise, Modeling of marginal burning state of fire spread in live chaparral 
shrub fuel bed, Combustion and Flame 143 (2005) 183-198.

[22] X. Zhou, S. Mahalingam, D. R. Weise, Experimental study and large eddy simulation of effect of terrain slope on burning in shrub fuel beds, Proceedings of the Combustion Institute 31 (2007) 2547-2555.

[23] W. Mell, A. Maranghides, R. McDermott, S. L. Manzello, Numerical simulation and experiments of burning douglas fir trees, Combustion and Flame 156 (2009) 2023-2041.

[24] D. Morvan, J. L. Dupuy, Modeling the propagation of a wildfire through a mediterranean shrub using a multiphase formulation, Combustion and Flame 138 (2004) 199-210.

[25] X. Zhou, D. R. Weise, S. Mahalingam, Experimental measurements and numerical modeling of marginal burning in live chaparral fuel beds, Proceedings of the Combustion Institute 30 (2005) 2287-2294.

[26] J. Lozano, W. Tachajapong, D. Weise, S. Mahalingam, M. Princevac, Fluid dynamic structures in a fire environment observed in laboratory-scale experiments, Combustion Science and Technology 182 (2010) 858-878.

[27] R. R. Linn, P. Cunningham, Numerical simulations of grass fires using a coupled atmosphere-fire model: Basic fire behavior and dependence on wind speed, Journal of Geophysical Research 110 (2005) 1-19.

[28] A. Dahale, S. Ferguson, B. Shotorban, S. Mahalingam, Effects of distribution of bulk density and moisture content on shrub fires, International Journal of Wildland Fire 22 (5) (2013) 625-641.

[29] S. B. Pope, Turbulent Flows, Cambridge University Press, 2000.

[30] W. Tachajapong, J. Lozano, S. Mahalingam, , X. Zhou, D. Weise, An investigation of crown fuel bulk density effects on the dynamics of crown fire initiation in shrublands, Combustion Science and Technology 180 (2008) 593-615.

[31] J. Li, Experimental investigation of bulk density and its role in fire behavior in live shrub fuels, Master's thesis, University of California Riverside (2011).

[32] F. Nmira, J. L. Consalvi, P. Boulet, B. Porterie, Numerical study of wind effects on the characteristics of flames from non-propagating vegetation fires, Fire Safety Journal 45 (2010) 129-141.

[33] X. Zhou, S. Mahalingam, A suitable mixture fraction for diffusion flames of wood pyrolysis gas, Combustion and Flame 133 (2003) 197-199.

[34] X. Zhou, S. Mahalingam, A flame surface density based model for large eddy simulation of turbulent non-premixed combustion, Physics of Fluids 14 (11) (2002) 77-80.

[35] B. P. Leonard, A stable and accurate convective modelling procedure based on quadratic upstream interpolation, Computer Methods in Applied Mechanics and Engineering 19 (1979) 59-98.

[36] J. C. F. Pereira, J. M. M. Sousa, Finite volume calculations of self-sustained oscillations in a grooved channel, Journal of Computational Physics 106 (1993) 19-29.

[37] E. E. Zukoski, Combustion Fundamentals of Fire, Academic Press, London, 1995.

[38] J. L. Dupuy, J. Marechal, D. Morvan, Fires from a cylindrical forest fuel burner: combustion dynamics 
and flame properties, Combustion and Flame 135 (2003) 65-76.

[39] G. Cox, R. Chitty, A study of the deterministic properties of unbounded fire plumes, Combustion and Flame 39 (1980) 191-209.

[40] E. E. Zukoski, Fluid dynamic aspects of room fires, in: Proceedings of the First International Symposium on Fire Safety Science, Hemisphere Publishing Corporation, Washington, 1986, pp. 1-30.

[41] Y. Hasemi, T. Tokunaga, Flame geometry effects on the buoyant plumes from turbulent diffusion flames, Fire Science and Technology 4 (1) (1984) 15-26.

[42] A. Hamins, T. Kashiwagi, R. Buch, Characteristics of pool fire burning, in: Fire Resistance of Industrial Fluids, American Society for Testing and Materials, 1995.

[43] G. Heskestad, SFPE Handbook of Fire Protection Engineering, 3rd Edition, National Fire Protection Association, 2002.

[44] A. L. Sullivan, P. F. Ellis, I. K. Knight, A review of radiant heat flux models used in bushfire applications, International Journal of Wildland Fire 12 (2003) 101-110.

[45] G. Heskestad, Flame heights of fuel arrays with combustion in depth, in: Proceedings of the Fifth International Symposium on Fire Safety Science, International Association for Fire Safety Science, 1997, pp. 427-438.

[46] F. Tang, L. H. Hu, M. A. Delichatsios, L. K. H, W. Zhu, Experimental study on flame height and temperature profile of buoyant window spill plume from an under-ventilated compartment fire, International Journal of Heat and Mass Transfer 55 (2012) 93-101.

[47] G. Heskestad, Dynamics of the fire plume, Philosophical Transactions of the Royal Society 356 (1998) $2815-2833$.

[48] W. K. George, R. L. Alpert, F. Tamanini, Turbulence measurements in an axisymmetric buoyant plume, International Journal of Heat Mass Transfer 20 (1977) 1145-1154.

[49] J. C. R. Hunt, A. A. Wray, P. Moin, Eddies, streams, and convergence zones in turbulent flows, Tech. Rep. CTR-S88, Center for Turbulence Research (1988).

[50] P. E. Desjardin, Modeling of conditional dissipation rate for flamelet models with application to large eddy simulation of fire plumes, Combustion Science and Technology 177 (2005) 1883-1916. 

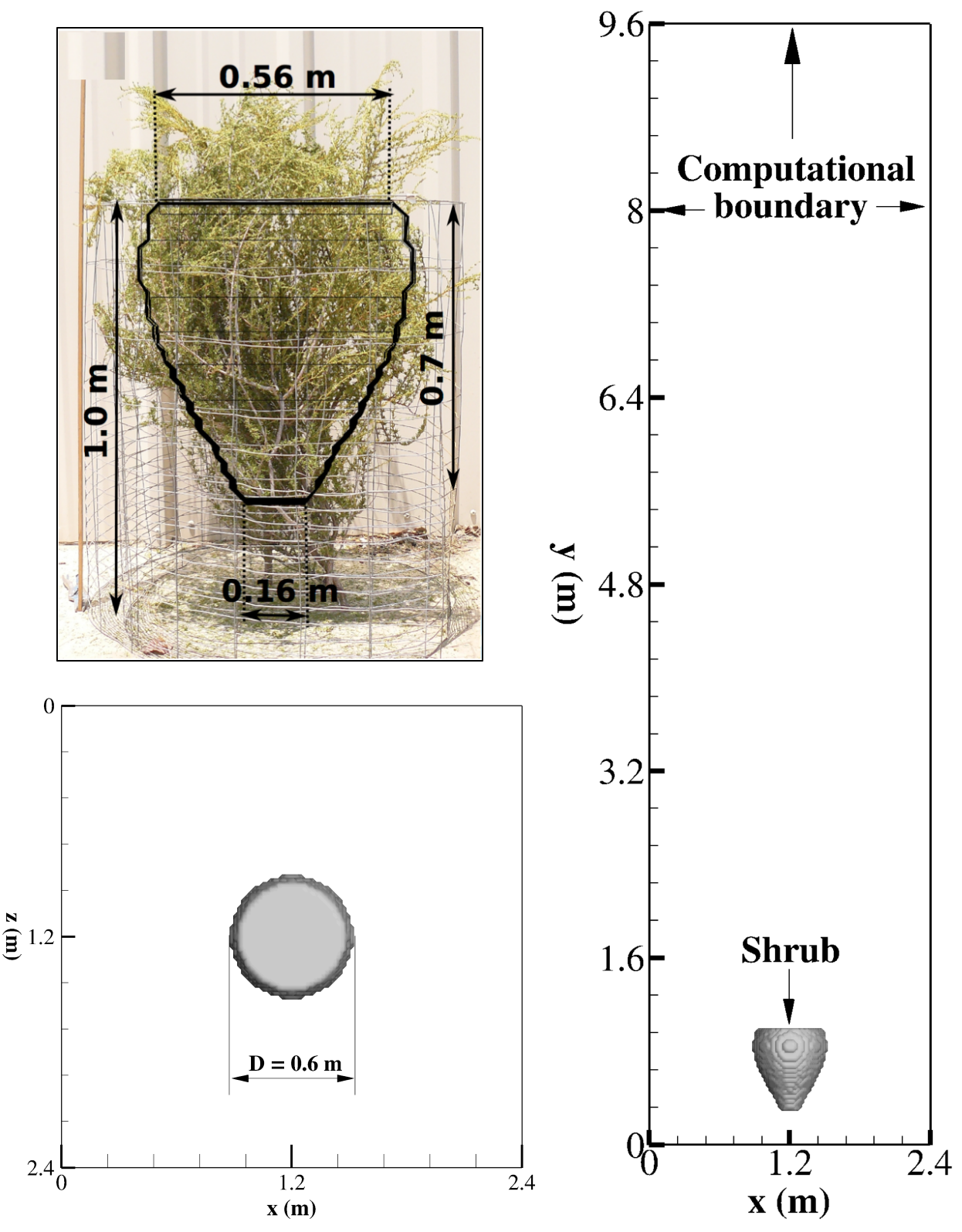

Figure 1: Schematic of computational domain. 


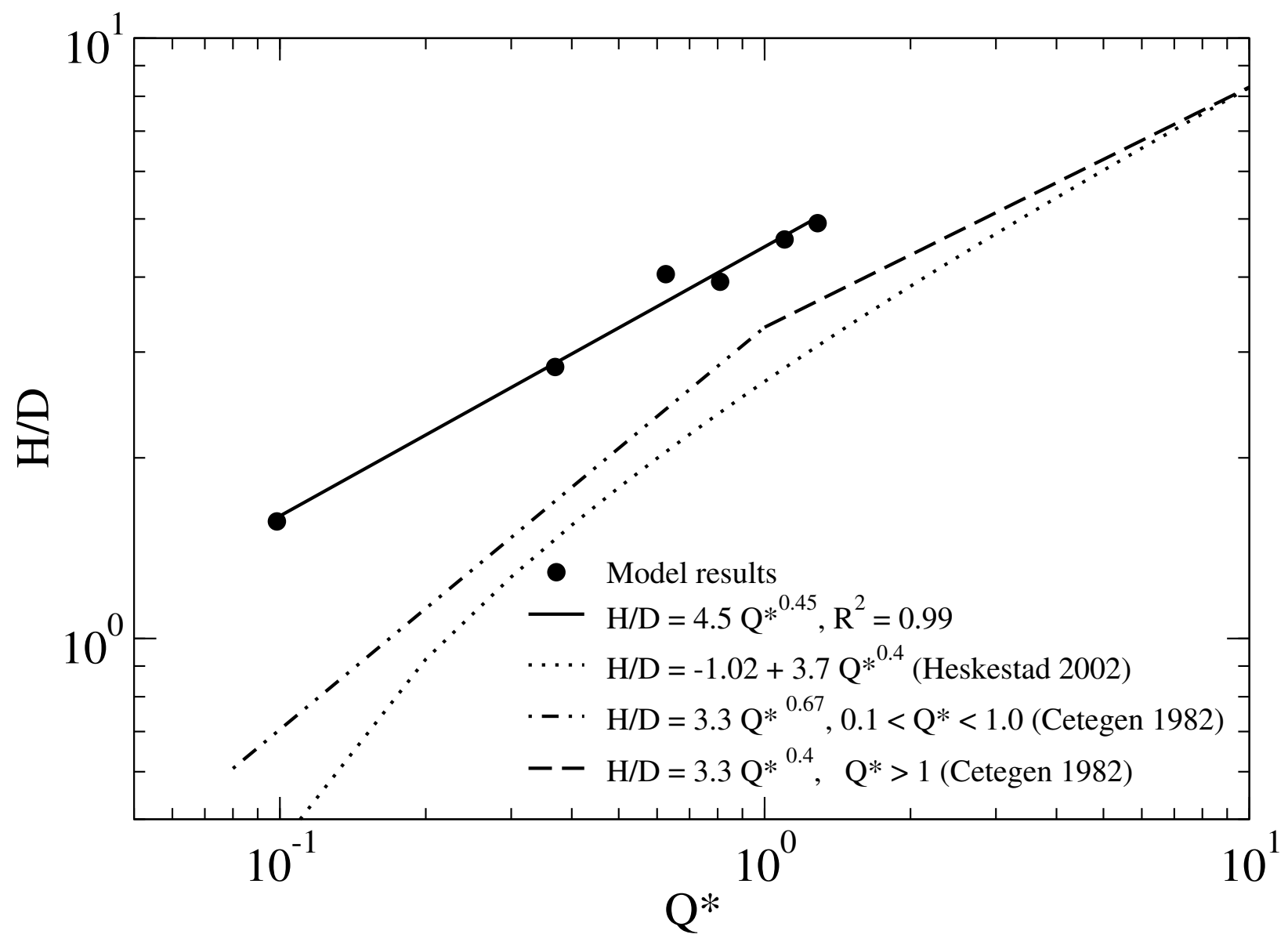

Figure 2: Dimensionless flame heights $(H / D)$ versus dimensionless heat release rate $\left(Q^{*}\right)$ for the six cases of bulk densities. Flame tip height is defined as the height at which gas phase temperature drops to $800 \mathrm{~K}$. Flame heights are measured from top surface of the shrub. Two-fifths power law from earlier studies is also shown for reference. For pool fires, the scaling law is $H / D=-1.02+3.7 Q^{* 0.4}$ [43]. Scaling laws for flame heights from buoyant diffusion flames over porous burners for two regimes of $Q^{*}$ are due to Cetegen [4]. 


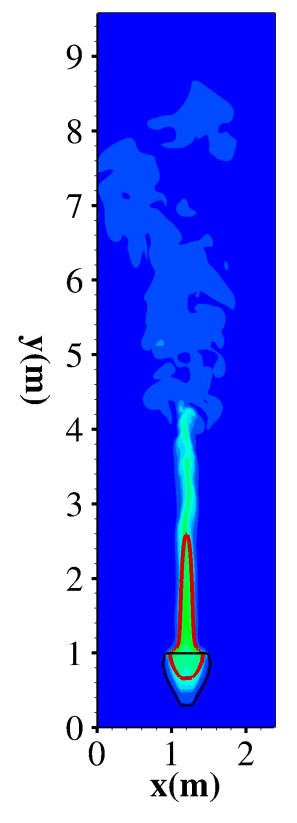

(a)

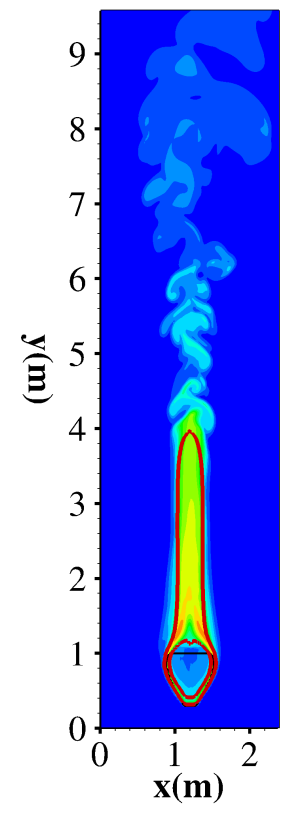

(b)

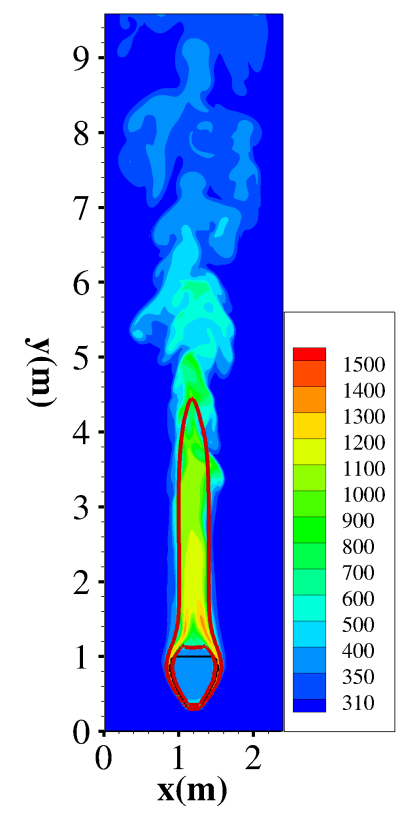

(c)

Figure 3: Contours of instantaneous gas phase temperature in Kelvin (color contours) and time-averaged gas phase temperature of $573 \mathrm{~K}$ (red line) along an $x y$-slice at $z=1.2 \mathrm{~m}$ for shrub bulk density of (a) $1 \mathrm{~kg} / \mathrm{m}^{3}$, continuous flame region is till $\mathrm{y} \approx 2.2 \mathrm{~m}$, intermittent flame region is between $2.2 \lesssim \mathrm{y} \lesssim 3.5 \mathrm{~m}$, and plume region is from $\mathrm{y} \gtrsim 3.5 \mathrm{~m}$ (b) $3 \mathrm{~kg} / \mathrm{m}^{3}$, continuous flame region is till $\mathrm{y} \approx 3.2 \mathrm{~m}$, intermittent flame region is between $3.2 \lesssim \mathrm{y} \lesssim 4.5$ $\mathrm{m}$, and plume region is from $\mathrm{y} \gtrsim 4.5 \mathrm{~m}$ (c) $5 \mathrm{~kg} / \mathrm{m}^{3}$, continuous flame region is till $\mathrm{y} \approx 4.2$ $\mathrm{m}$, intermittent flame region is between $4.2 \lesssim \mathrm{y} \lesssim 5.0 \mathrm{~m}$, and plume region is from $\mathrm{y} \gtrsim 5.0$ m. 


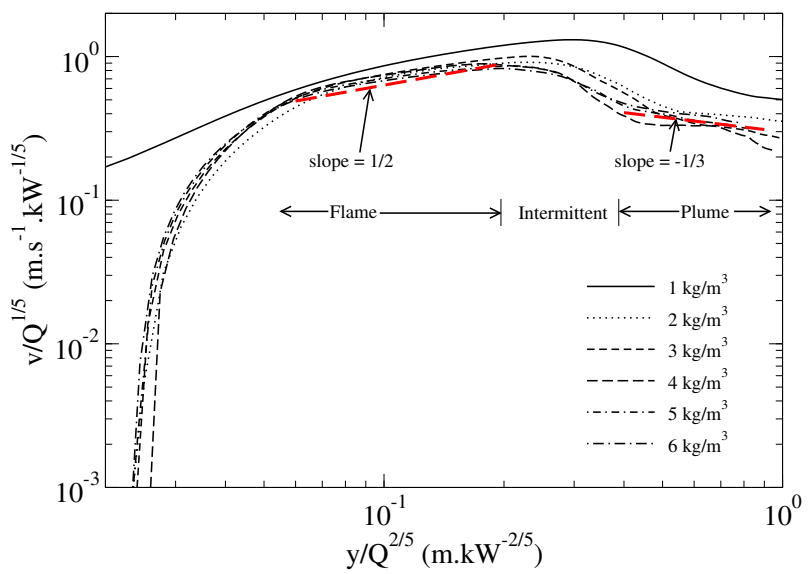

(a)

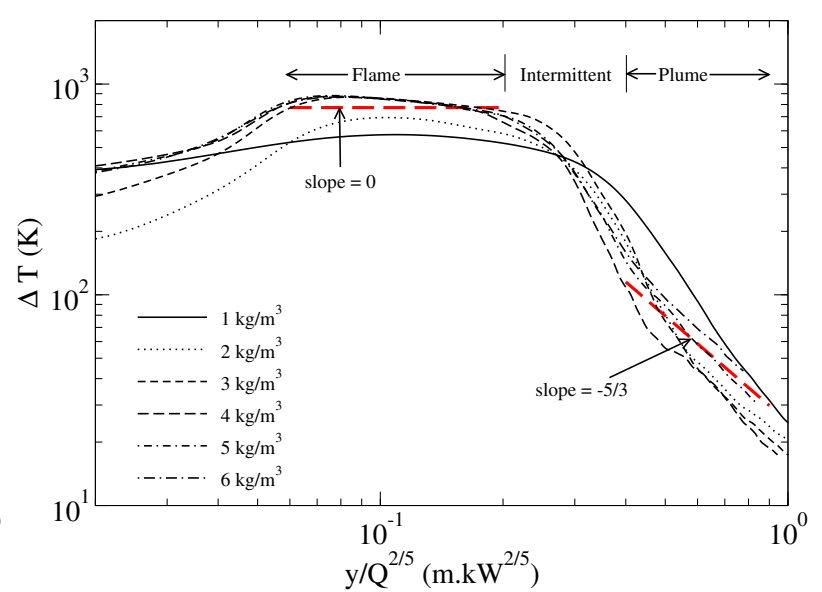

(b)

Figure 4: Centerline profiles along the plume axial location for various bulk densities, (a) time-averaged axial velocity; (b) time-averaged gas phase temperature.

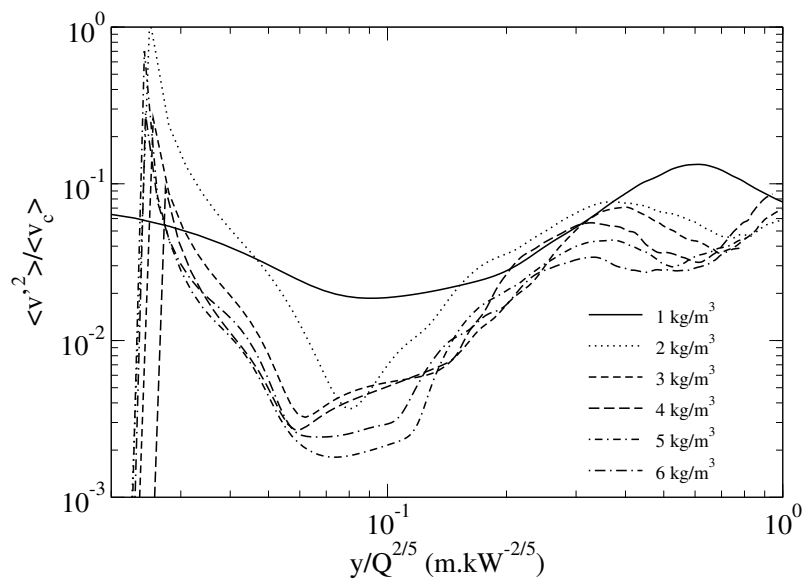

(a)

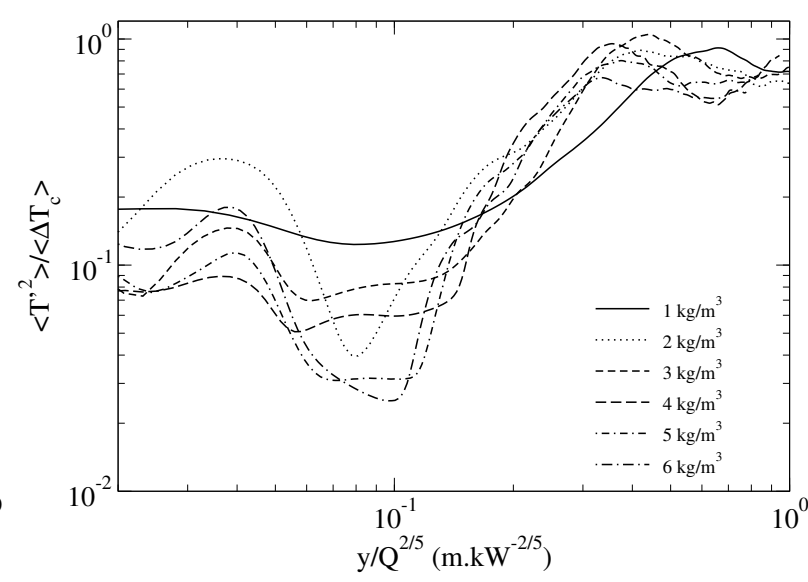

(b)

Figure 5: Centerline profiles along the plume axial location for various bulk densities, (a) root mean square of axial velocity normalized with the centerline time-averaged velocity; (b) root mean square of gas phase temperature normalized with centerline time-averaged gas phase temperature. 


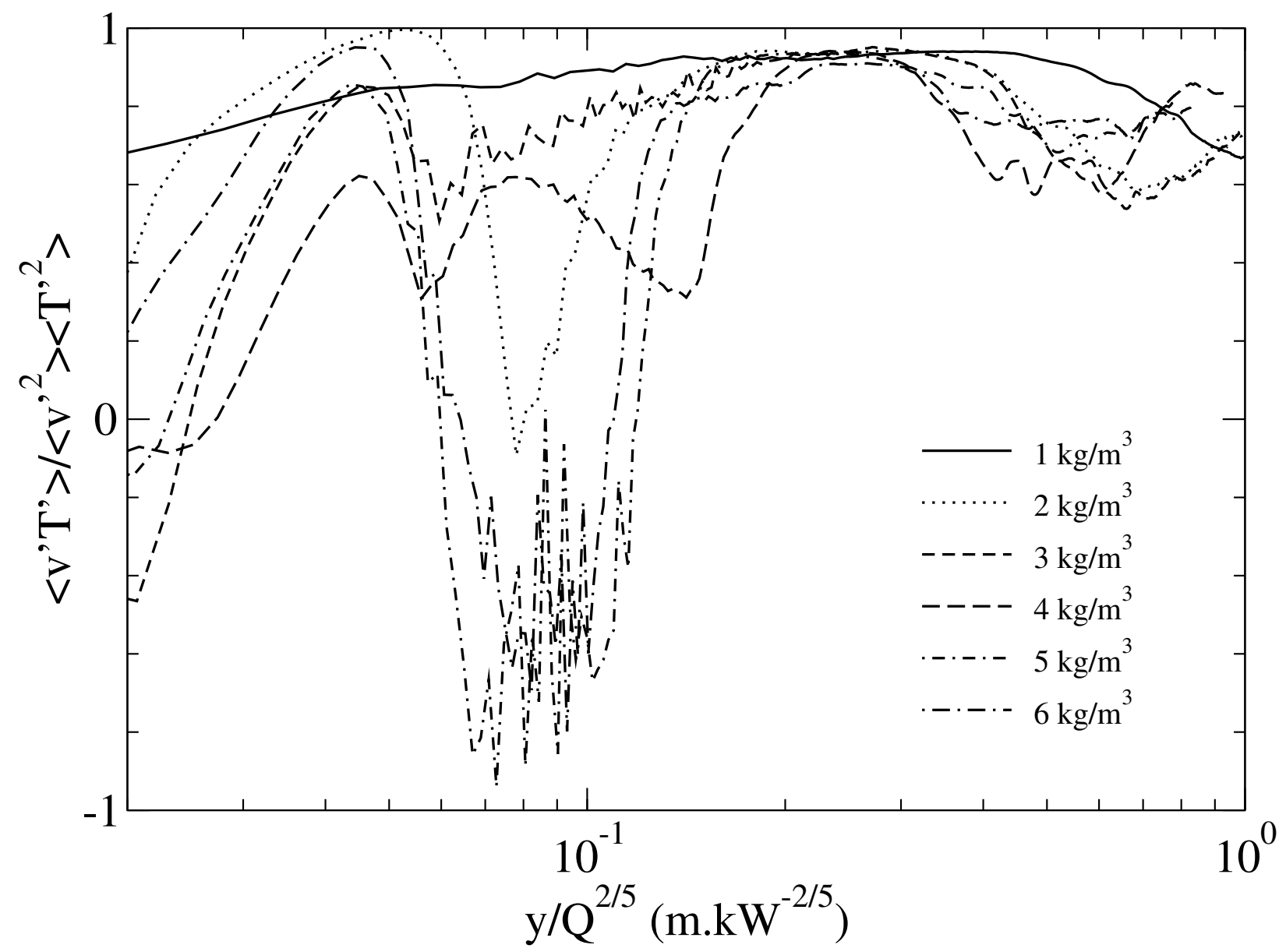

Figure 6: Centerline profiles for axial velocity-temperature correlation for various bulk densities as a function of plume axial location for various bulk densities. 


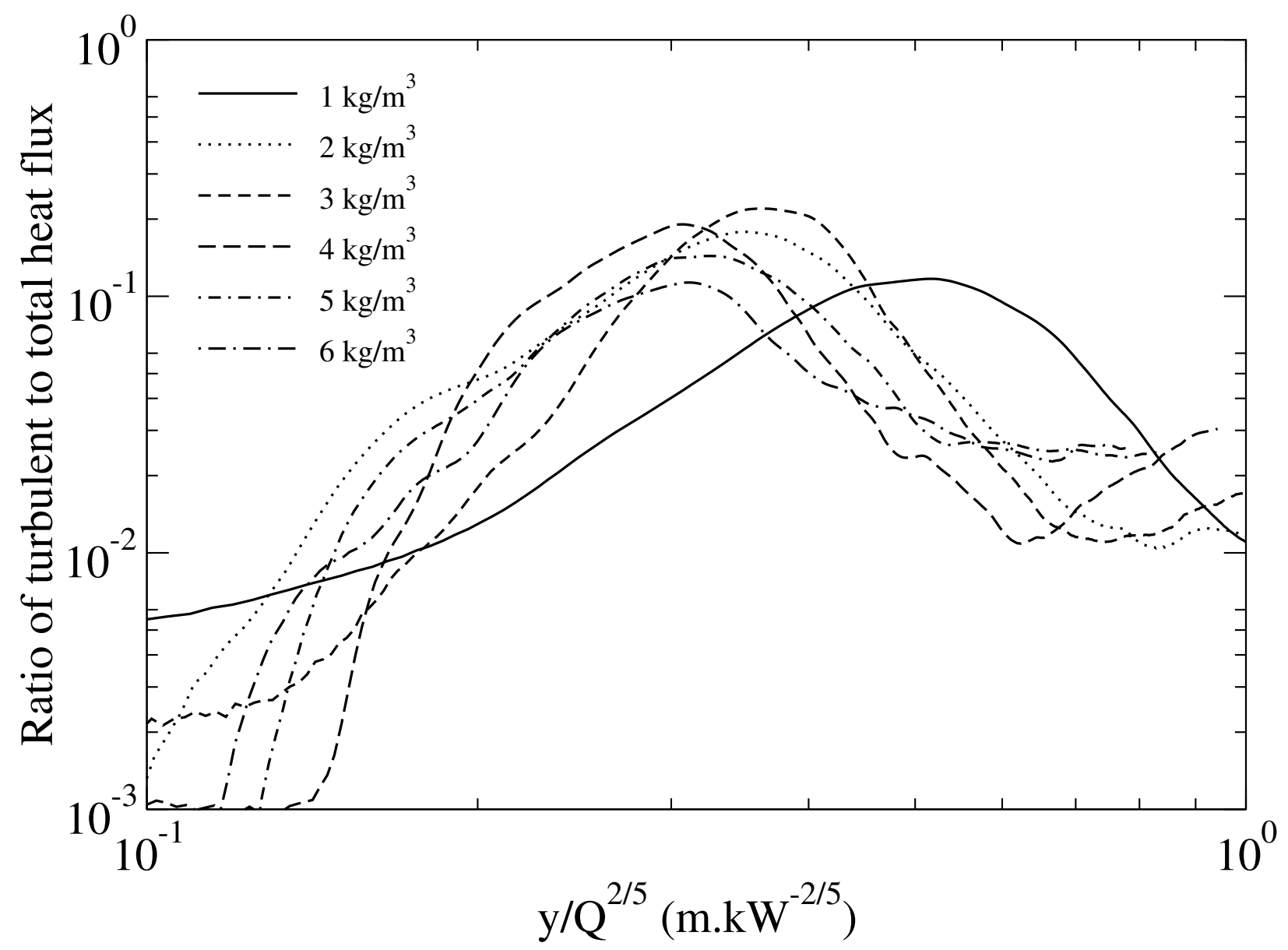

Figure 7: Ratio of turbulent to mean convective heat flux along the centerline of the domain for various bulk densities. 


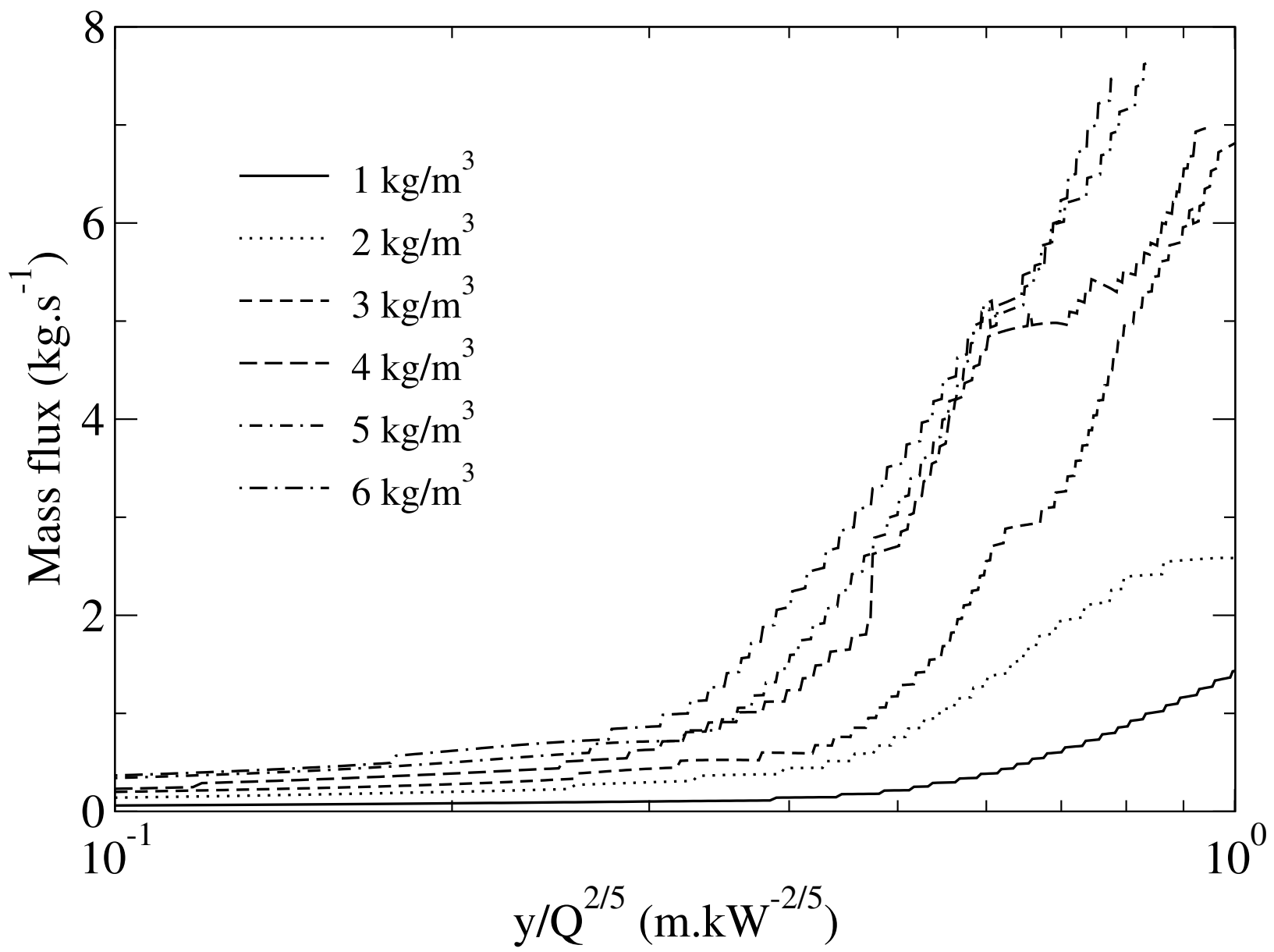

Figure 8: Centerline profiles for mass flux at various heights of the domain for various bulk densities. 


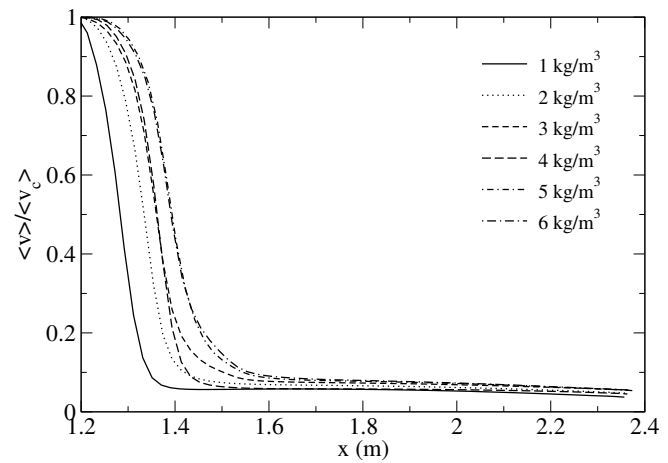

(a)

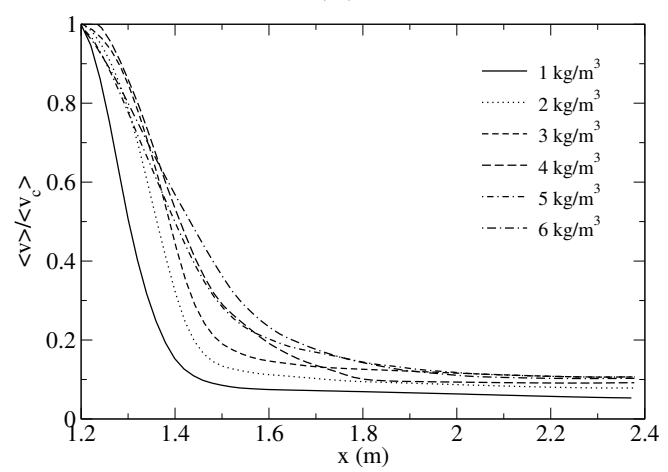

(c)

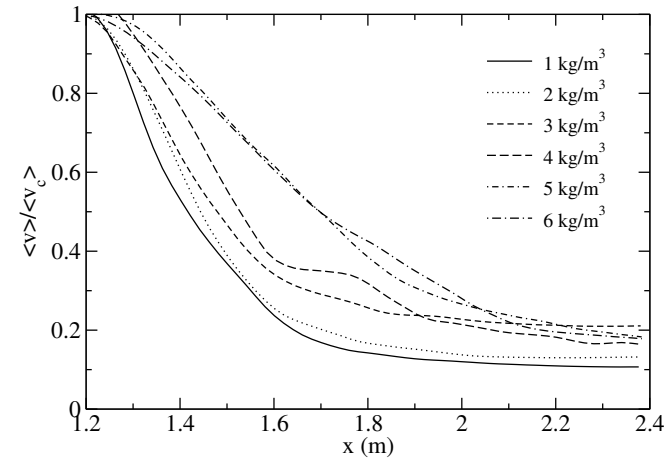

(e)

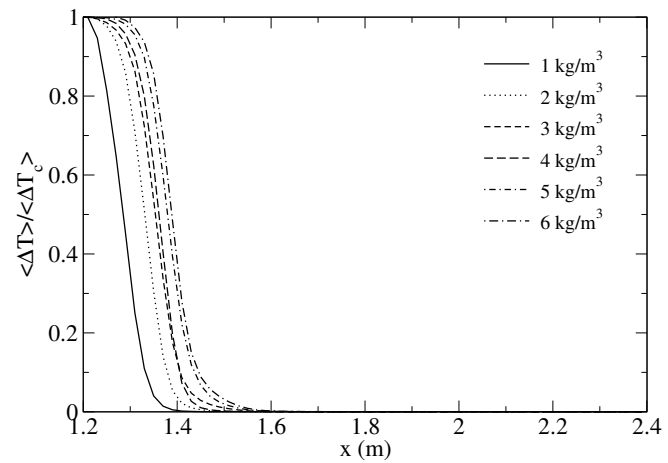

(b)

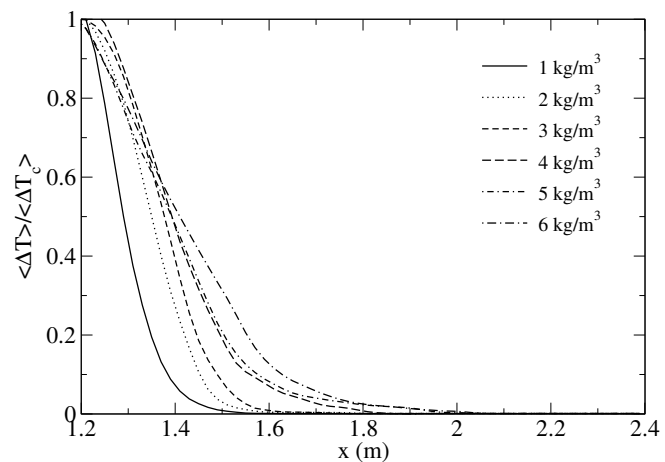

(d)

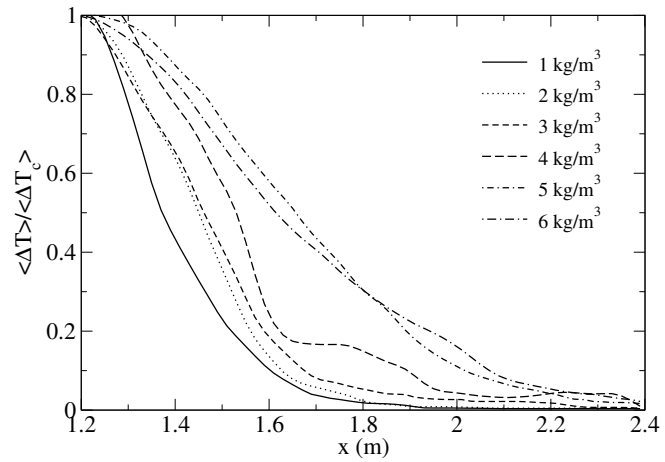

(f)

Figure 9: Transverse profiles for time-averaged vertical velocity normalized by time-averaged centerline vertical velocity (a,c,e) and time-averaged gas phase temperature rise $\left(T-T_{\infty}\right)$ normalized by temperature rise along the centerline of domain $(b, d, f)$ at various heights. The heights are chosen in the continuous flame region $\left(T_{c}=873 \mathrm{~K}\right)$, intermittent flame region $\left(T_{c}=573 \mathrm{~K}\right)$ and thermal plume region $\left(T_{c}=373 \mathrm{~K}\right)$. 


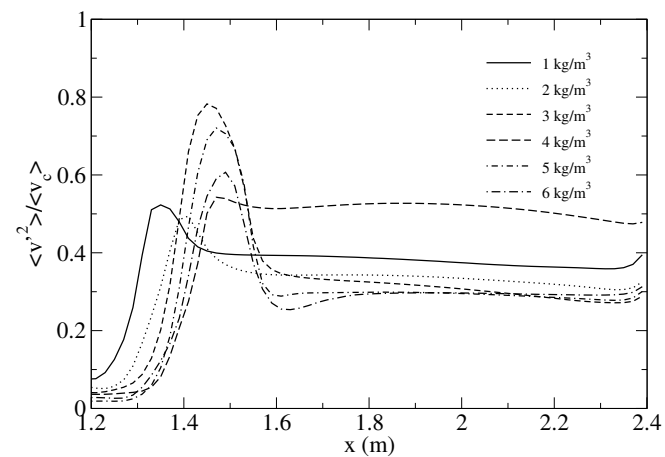

(a)

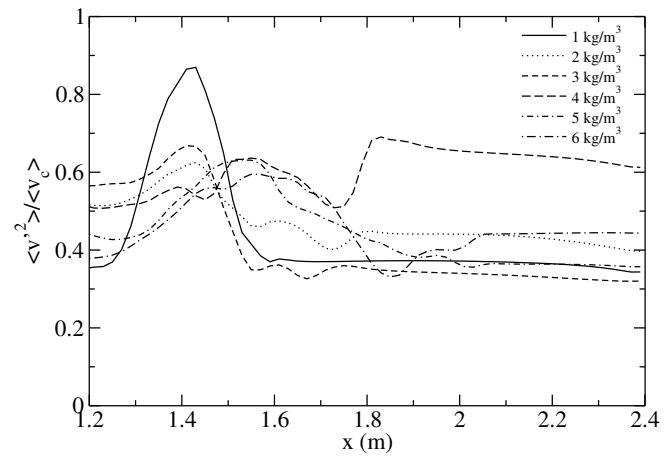

(c)

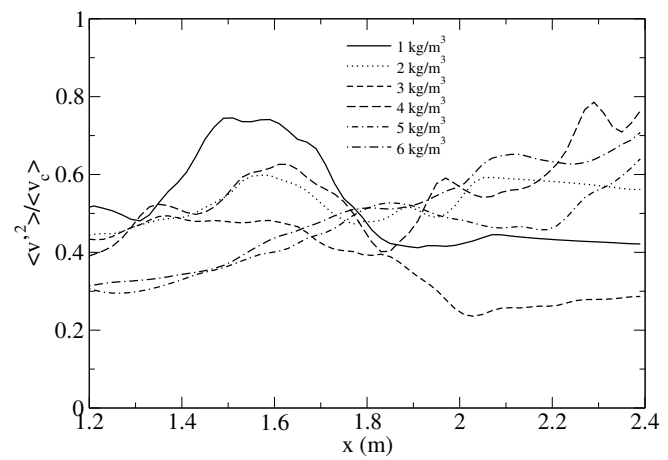

(e)

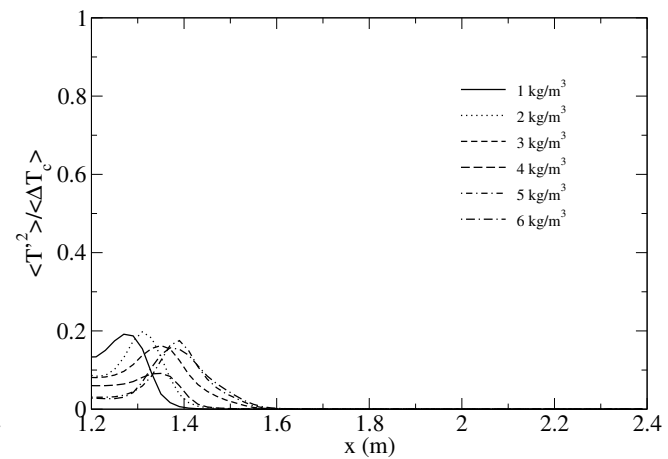

(b)

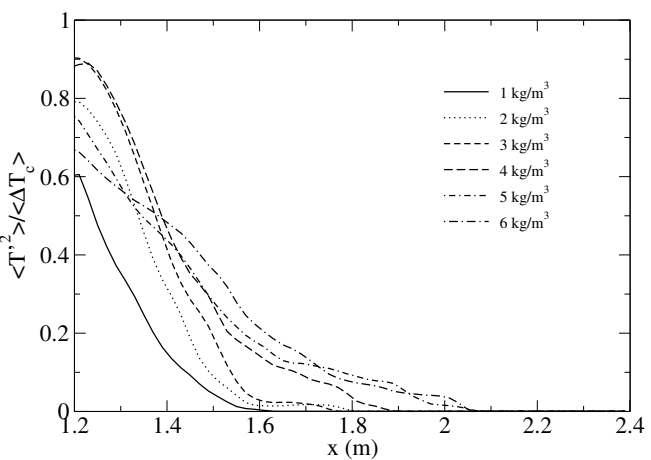

(d)

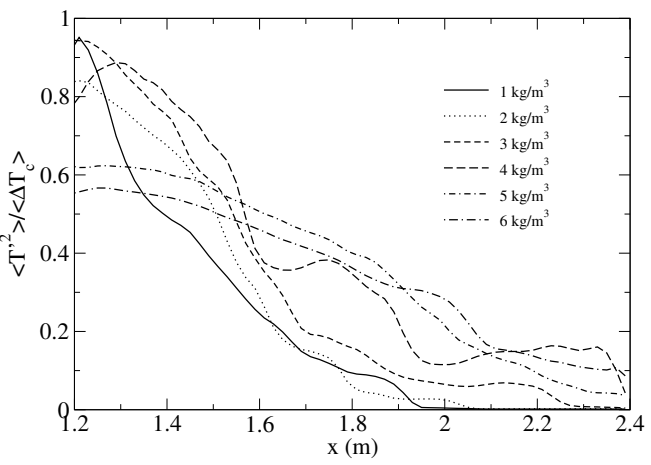

(f)

Figure 10: Transverse profiles for r.m.s. of vertical velocity normalized by time-averaged centerline vertical velocity $(\mathrm{a}, \mathrm{c}, \mathrm{e})$ and r.m.s. of gas phase temperature normalized by temperature rise along the centerline of domain $(b, d, f)$ at various heights. The heights are chosen in the continuous flame region $\left(T_{c}=873 \mathrm{~K}\right)$, intermittent flame region $\left(T_{c}=573 \mathrm{~K}\right)$ and thermal plume region $\left(T_{c}=373 \mathrm{~K}\right)$. 


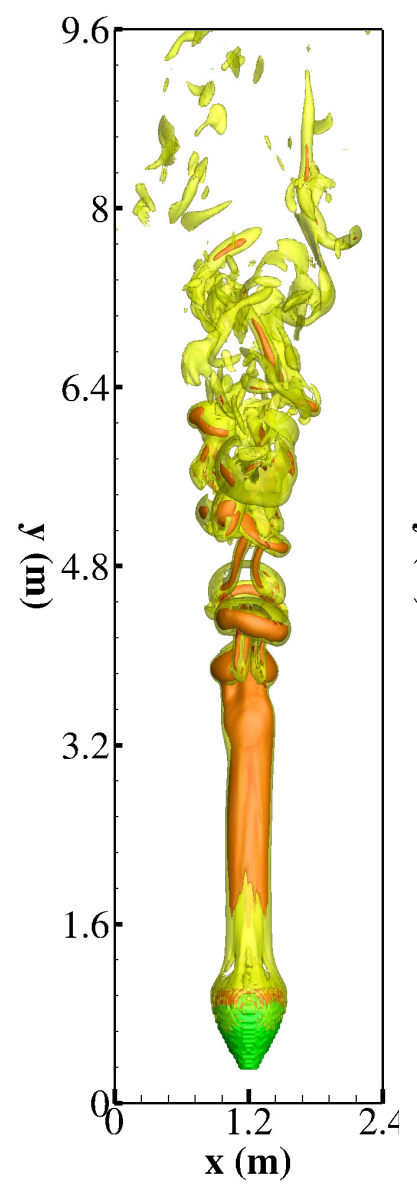

(a)

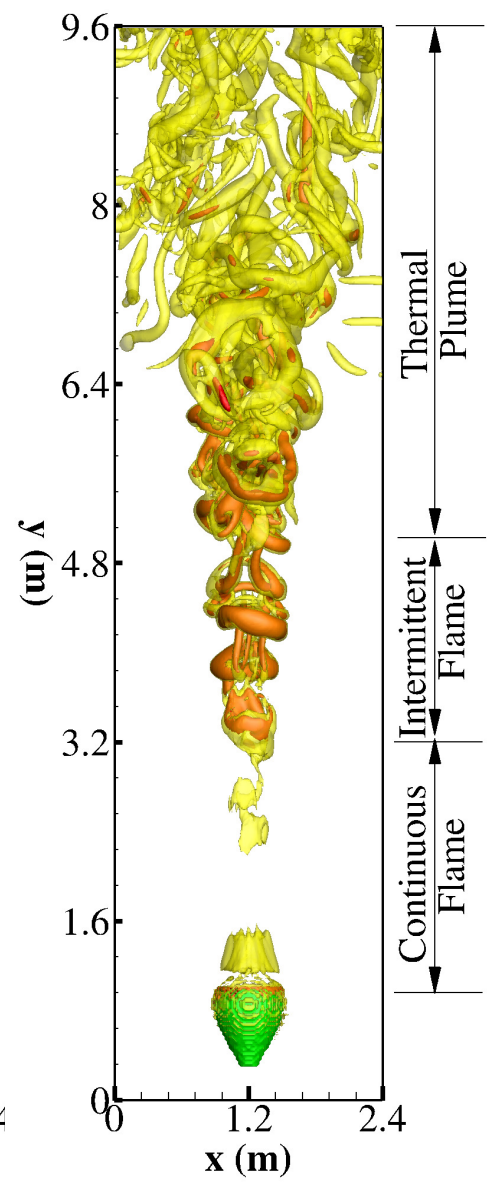

(b)

Figure 11: (a) Isosurfaces of instantaneous vorticity magnitude at $30 \mathrm{~s}^{-1}$ (yellow) and $60 \mathrm{~s}^{-1}$ (red) for a shrub bulk density of $3 \mathrm{~kg} / \mathrm{m}^{3}$ (green); (b) Isosurfaces of instantaneous second invariant of velocity gradient tensor at $30 \mathrm{~s}^{-2}$ (yellow) and $300 \mathrm{~s}^{-2}$ (red) for a shrub bulk density of $3 \mathrm{~kg} / \mathrm{m}^{3}$ (green). 